\title{
寛骨臼両柱骨折に対する観血的治療
}

\author{
久留米大学整形外科 \\ 白 濱 正 博・永 田見 生 \\ 坂 井健介・田中邦彦 \\ 済生会福岡総合病院整形外科 \\ 阿部 隆 信 - 遠 藤 俊 也 \\ 久保学 \\ 熊本セントラル病院整形外科 \\ 井上雅文 - 内川知也
}

\section{Operative Treatment of Both Column Fractures in the Acetabulum}

\section{Masahiro Shirahama, Kensei Nagata, Kunihiko Tanaka, and Kensuke Sakai}

Department of Orthopaedic Surgery, Kurume University School of Medicine, Kurume, Fukuoka, Japan

Takanobu Abe, Toshiya Endo, and Manabu Kubo

Department of Orthopaedic Surgery, Saiseikai Fukuoka General Hospital, Fukuoka, Japan

\section{Masabumi Inoue, and Tomoya Utikawa}

Department of Orthopaedic Surgery, Kumamoto Central Hospital, Kumamoto, Japan

We treated 13 both column fractures of the acetabulum using open reduction and internal fixation, in 10 males and 3 females with a mean age of 47.9 years from 1994 to 2000 . The interval from injury to operation was 14.3 days. We performed the anterior approach on 2 cases, combined approach on 11, and simultaneous anterior and posteriol approach on 3. Bleeding during operation ranged $1300 \mathrm{ml}$ to $3520 \mathrm{ml}$, operation time 4 hours to 7 hours 50 minutes. The average follow-up period was 27 months. There was one case with poor JOA score and two cases evaluated as unsatisfactory according to radiographical findings. We recommend that open reduction and internal fixation should be performed for both column fractures of the acetabulum.

Key words : acetabulum (寛骨臼), both column fractures（両柱骨折）, combined approach（複合進 入路)

は じめに

骨盤骨折のなかであ，骨折が股関節におよぶ寛骨臼 骨折は, 関節内骨折として関節面の解剖学的整復が要 求される重要な骨折である. なかでも前柱, 後柱の骨 折に伴い関節面が大きく転位した両柱骨折は, 進入法
や整復固定が難しく治療に難渋する．今回我々はこの 両柱骨折に対し積極的に観血的治療を行ってきたので 経過を報告する．

\section{対象および方法}

症例は 1994 年から 2000 年までに治療した男性 10 


\begin{tabular}{l|cccc}
\multicolumn{5}{c}{ 表 2. 治療成績 } \\
\hline \hline \multicolumn{1}{c|}{ JOA スコア } & $\begin{array}{c}\text { 優 } \\
100-90\end{array}$ & $\begin{array}{c}\text { 良 } \\
89-80\end{array}$ & $\begin{array}{c}\text { 可 } \\
79-60\end{array}$ & $\begin{array}{c}\text { 不可 } \\
59-\end{array}$ \\
\hline & 7 & 2 & 3 & 1 \\
X線学的評価 & 5 & & & \\
Anatomical (0-1mm) & 2 & 2 & 1 & \\
Satisfactoriy (2-3mm) & & & 1 & 1 \\
Unsatisfactory (3mm<) & 異所性骨化 & 異所性骨化 & 術後感染 & 坐骨神経麻痺 \\
合併症 & $(1$ 例 $)$ & (1 例) & OA & OA
\end{tabular}

表 1. 進入路之術中出血, 手術時間

\begin{tabular}{|c|c|c|c|c|c|}
\hline \multirow{2}{*}{\multicolumn{2}{|c|}{$\begin{array}{l}\text { lliofemoral approach } \\
\text { (2) }\end{array}$}} & \multicolumn{4}{|c|}{ Combined approach } \\
\hline & & \multicolumn{2}{|c|}{$\begin{array}{c}\text { 前後同時 } \\
(3)\end{array}$} & \multicolumn{2}{|c|}{$\begin{array}{c}\text { 体位変換 } \\
(8)\end{array}$} \\
\hline 1360 & 2.40 & 3100 & 4 & 1300 & 4 \\
\hline \multirow[t]{7}{*}{5200} & 5 & 1950 & 4.50 & 2400 & 5 \\
\hline & & 3520 & 6 & 2535 & 5 \\
\hline & & & & 1800 & 5.30 \\
\hline & & & & 2055 & 6 \\
\hline & & & & 2240 & 6 \\
\hline & & & & 2885 & 7.50 \\
\hline & & & & 4200 & 9 \\
\hline 平均: $3280 \mathrm{~g}$ & $3.20 \mathrm{hr}$ & $856.7 \mathrm{~g}$ & $4.57 \mathrm{hr}$ & $426.9 \mathrm{~g}$ & $6.25 \mathrm{r}$ \\
\hline
\end{tabular}

例, 女性 3 例の 13 例で, 年齢は 20 歳から 85 歳, 平 均 47.9 歳, 受傷原因は交通事故が 9 例, 転倒転落が 4 例である. 多くが high energy 外傷のため出血性 ショックで搬入され，頭部損傷や多発骨折を合併して いた，受傷から手術までは 5 日から 23 日，平均 14 日 で, 術後経過観察期間は 6 か月から 5 年, 平均 2 年 3 か月であった。寛骨臼骨折型はJudet \& Letournel の分類を用いた。進入路は iliofemoral approach が 2 例で, ilioinguinal approach と KocherLangenbeck approachを併用した combined approach が 11 例であった. 8 例は術中体位変換して進 入したが， 3 例は floppy lateral position で前後から 同時に進入し手術をおこなった。

\section{結果}

各進入路と術中出血, 手術時間は表 1 に示すように, iliofemoral approach が平均 $3280 \mathrm{~g}, 3$ 時間 20 分, combined approach では, 前後同時が平均 $2856.7 \mathrm{~g}$,
4 時間 57 分で, 術中体位を変換した症例では $2426.9 \mathrm{~g}, 6$ 時間 25 分と, どの進入路む大量の出血之 手術時間を必要とし大きな侵襲を与えていた。車椅子 または免荷起立までの離床期間は，合併損傷がない例 では平均 22.7 日と早かったが，上下肢に合併損傷が ある例では 47.5 日と少し遅れていた。 また, 進入路 とX線学的評価では，ほとんどが anatomical 又は satisfactory であったが, $3 \mathrm{~mm}$ 以上の unsatisfactory が combined approach に2 例に残存していた.

治療成績は日整会股関節機能判定, JOA スコアを 用いた，優が 7 例, 良が 2 例, 可が 3 例, 不可が 1 例 で, X 線学的評価で $3 \mathrm{~mm}$ 以上が可と不可に各々 1 例であった。術後の合併症としては, 優と良に Brooker Grade-1の異所性骨化がみられたが成績に 支障無く, 可の 1 例は糖尿病があり術後感染を来たし, 不可の 1 例は受傷時の坐骨神経麻痺と整復不良による 関節症を来たし，成績に影響したと思われる（表 2 ）。

\section{症例 供 覧}

症例 $1 ： 71$ 歳男性, バイク走行中バイクと衝突受 傷. いわゆる中心性脱臼を伴う両柱骨折で, 側方牽引 を追加したが整復は得られなかった（図 1 ). 受傷 14 日目 floppy lateral position で前後から同時に進入し, 術中出血 $1950 \mathrm{ml} ４$ 時間 50 分で観血的整復固定術を おこなった。 術後 2 週で車椅子移動, 3 週で松葉杖に て起立歩行が可能亡なり, 術後 2 年の現在, Brooker Grade-1の異所性骨化がみられるが日常生活に支障な く, JOA スコア 90 点で優である(図 2 ).

症例 $2: 57$ 歳男性, トラックの荷台から転落受傷. 中心性脱臼を伴う両性骨折である. Judet view で関 節面の大きな転位を認め, 側方牽引を追加したが整復 は得られなかった。 CTで関節内側, いわゆる 


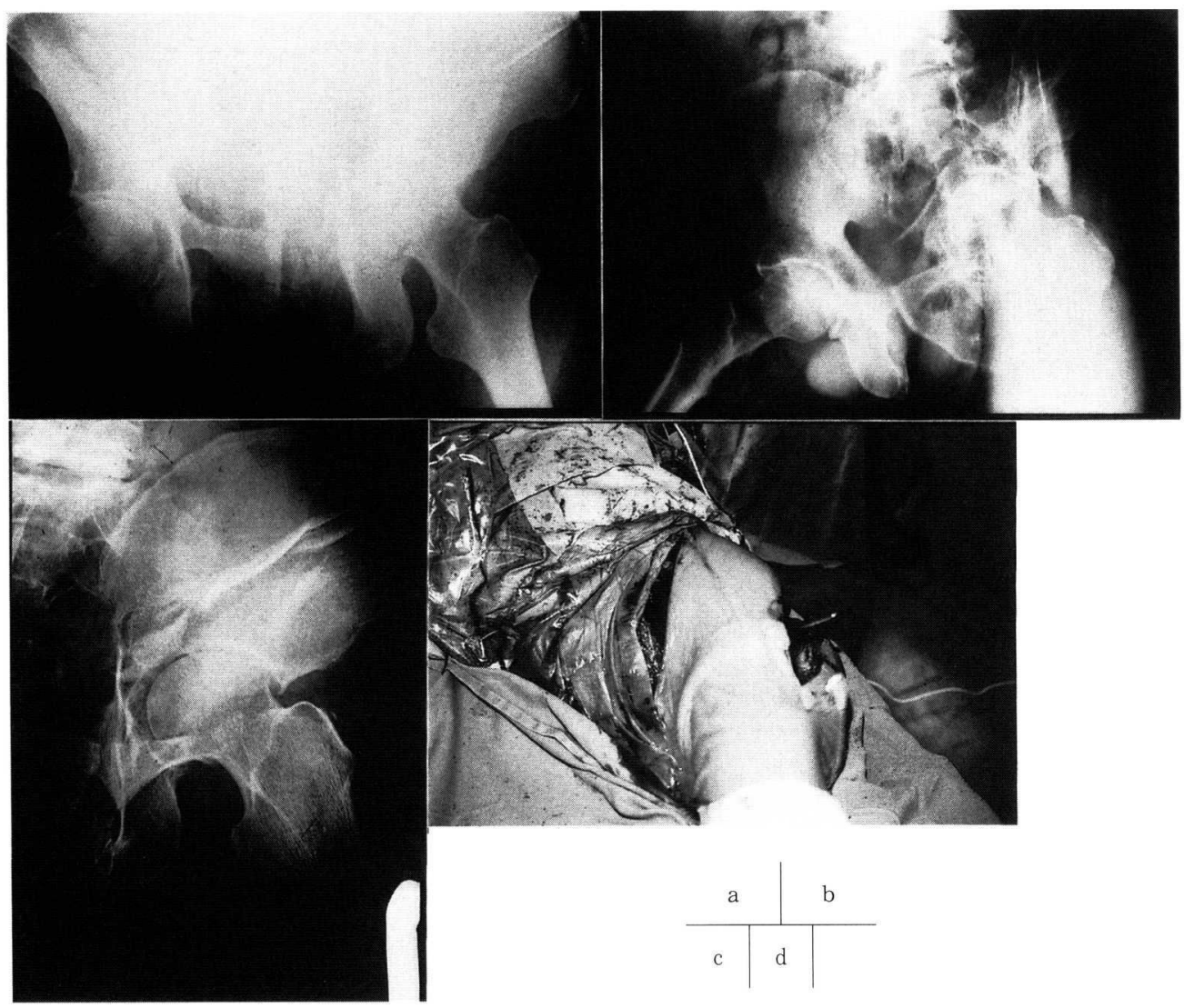

図 1 症例 171 歳 男性 受傷時
a. X線前後像
b, c. Judet view
d. floppy lateral position

表 3. Combined approach による著家の侵襲

\begin{tabular}{l|cccc}
\hline \hline & $\begin{array}{c}\text { J. A. Goulet } \\
(31 \text { 例 })\end{array}$ & $\begin{array}{c}\text { A. Moronie } \\
(18 \text { 例 })\end{array}$ & $\begin{array}{c}\text { C. Routt } \\
(21 \text { 例 })\end{array}$ & $\begin{array}{c}\text { 当科 } \\
(13 \text { 例 })\end{array}$ \\
\hline 時間 (hr.) & 4.5 & 5.2 & 6.0 & 5.4 \\
& $(2.5 \sim 9.0)$ & $(4.0 \sim 6.0)$ & $(5.0 \sim 9.0)$ & $(4.0 \sim 9.0)$ \\
出血 (g) & 1150 & 1641 & 1878 & 2641.8 \\
X線評価 & 94 & 89.9 & 88 & 84.6 \\
$(3 \mathrm{~mm}<, \%)$ & & & &
\end{tabular}

Quadrilateral surface の骨片が認められ，3D-CT で はさらに詳しく骨片の部位，転位方向が把握できた (図 3 ). 手術は combined approach を用いて, 後壁 を ribbon で整復固定し，後柱，前柱，前壁を reconstraction plate で整復固定, さらにQuadrilateral surface を腸骨骨片を伴った cableで整復固定し
た. 術後 3 日より CPM を開始し, 3 週で免荷起立歩 行, 12 週で全荷重歩行とし, JOA スコアは 92 点で 優であった(図 4 ).

考 察

両柱骨折に対する進入路は, 外側から入る, いわゆ 

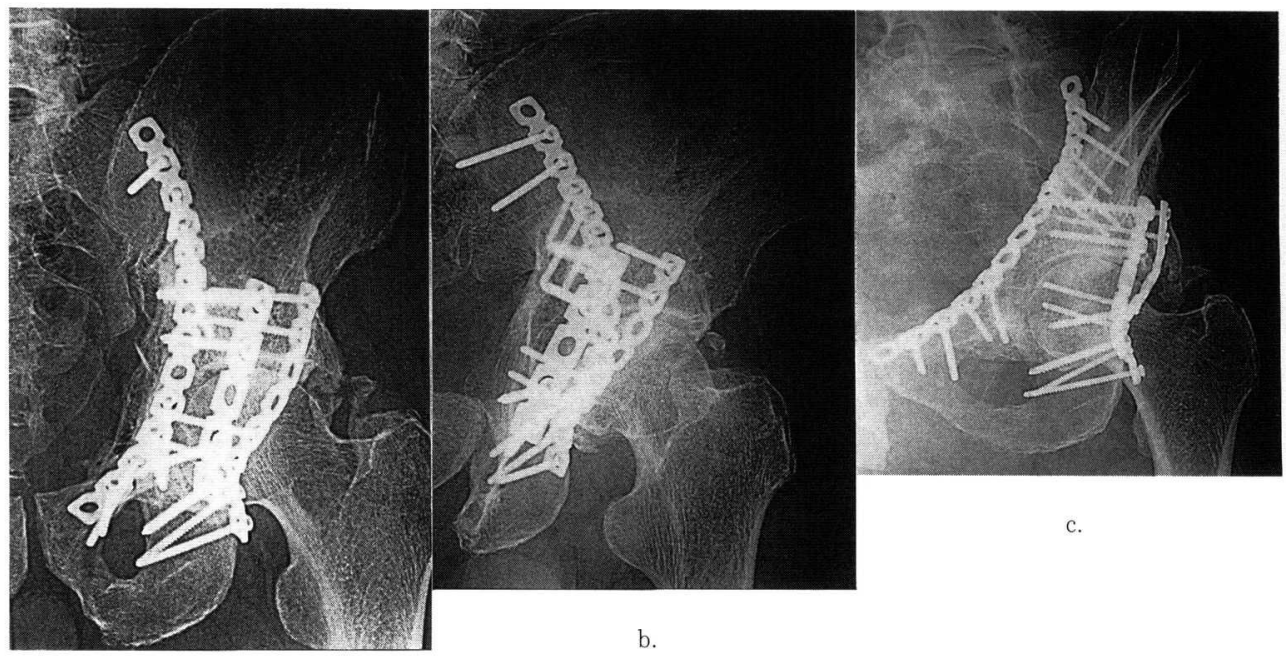

a.

図 2 症例 1 術後

a. X線前後像 b, c. Judet view

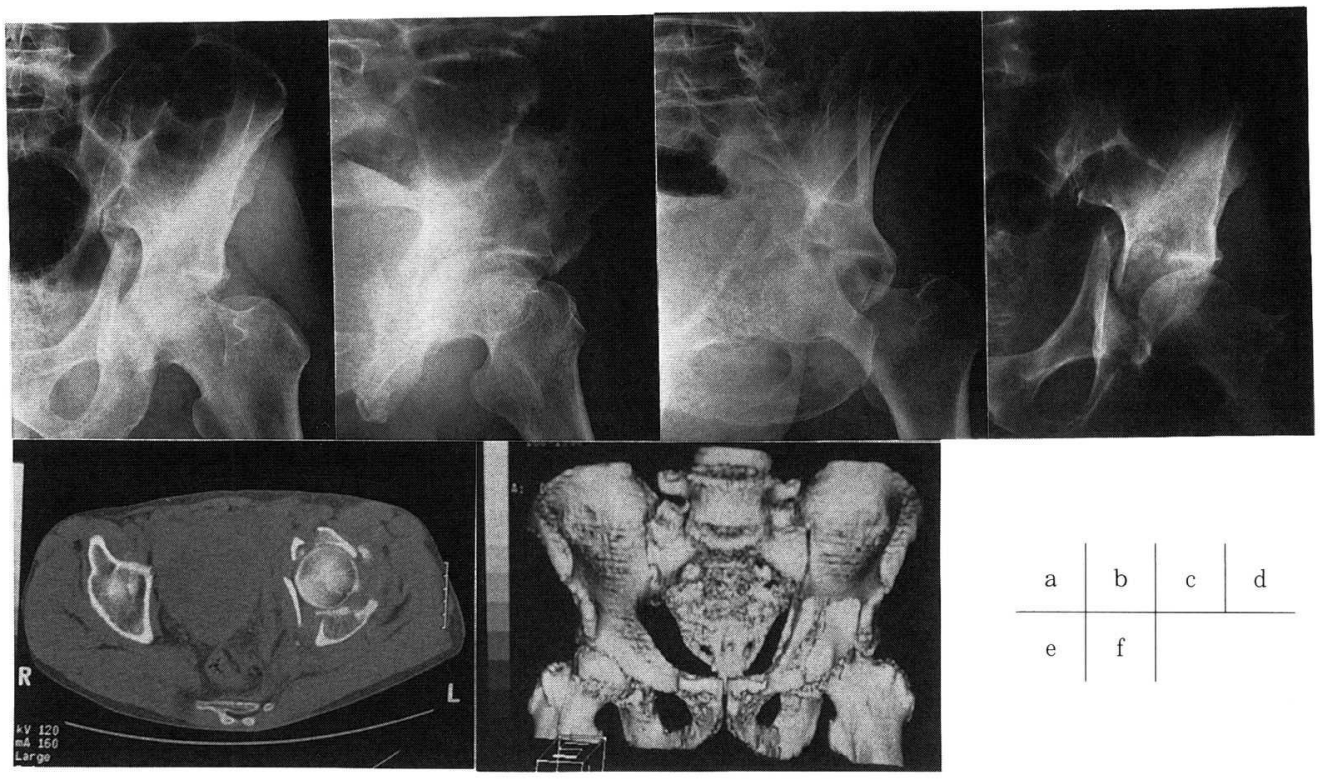

図 3 症例 2 57歳 男性 受傷時
a. X線前後像
b, c. Judet view
d. 側方率引
e. CT
f. $3 \mathrm{D}-\mathrm{CT}$ 


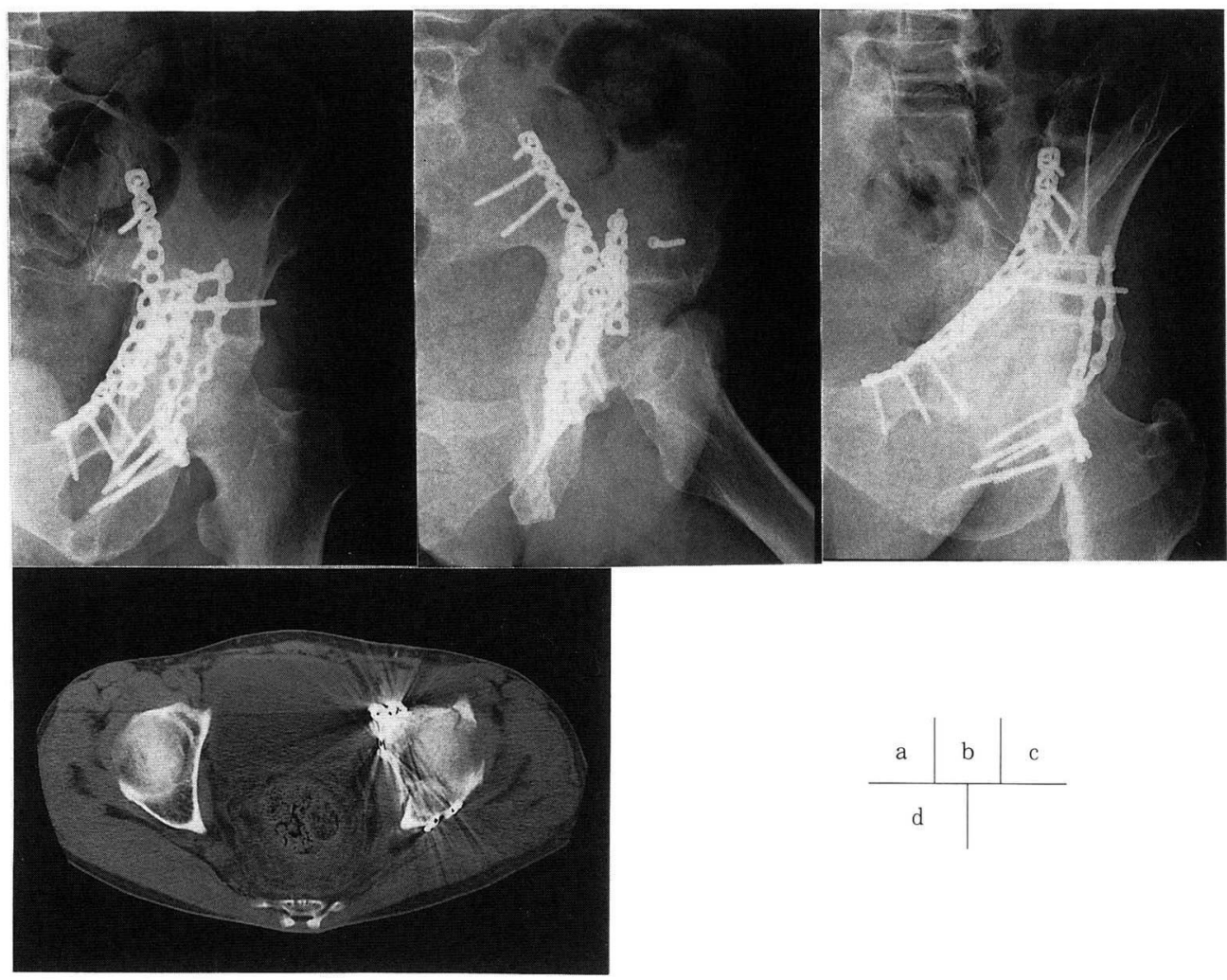

図 4 症例 2 術後

a. X線前後像 b, c. Judet view d. CT

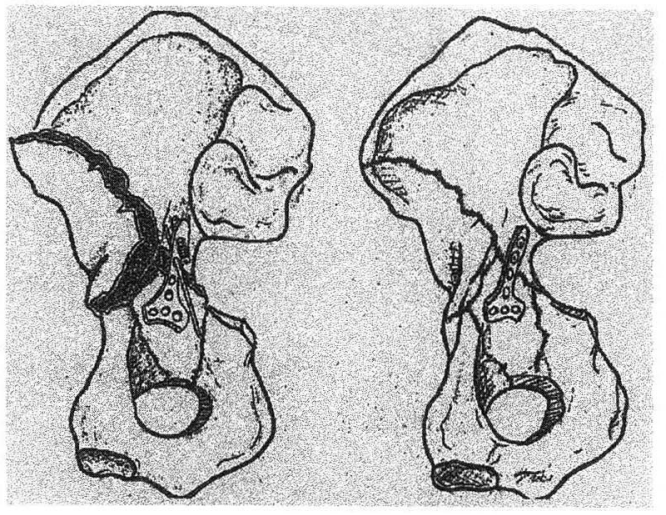

a.

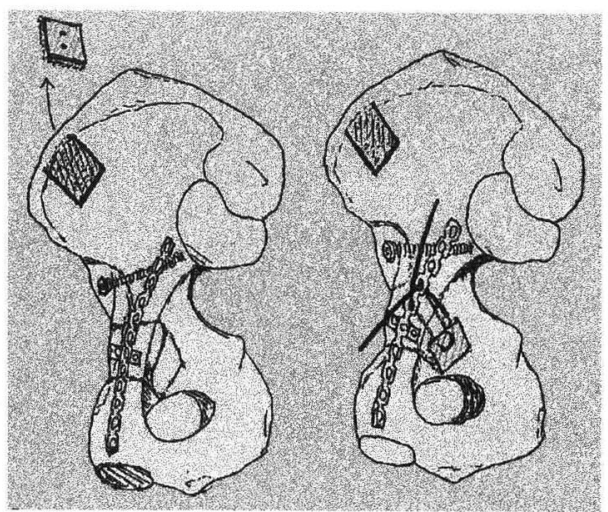

b.

図 5 臼蓋底, quadriluteral surface の固定法

a. Dean Cole らのPlate を用いた方法

b. ケーブルと骨移植を併用した方法 
る拡大進入路か, 前方および後方からの複合進入路の どちらかである. 拡大進入路は十分な視野の確保が出 来, 整復固定操作む容易ではあるが, 侵襲が大きすぎ るため, Alonso ら ${ }^{1)}$ はextended ilio-femoral approach で $86 \%$, triradiate approach で $53 \%$,

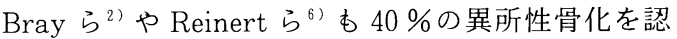
め, 外転筋力低下や媣部感染, 坐骨神経麻痺などの合 併症む多いためあまり推薦されなくなった，複合進入 路 (combined approach) は, やせた症例では floppy lateral position で前後同時に進入できるが, 一般に 体位変換が必要となり手術時間も長くなる. Goulet ら (4) や諸家 ${ }^{5(6) 7)}$ の報告を見てあ, 手術時間, 出血と もに大きな侵襲となっており，当科でも $2641.8 \mathrm{ml}$ と かなり大きな侵襲となっていた。しかし，X線学的に は関節面は $3 \mathrm{~mm}$ 以下の解剖学的整復が 88 94\%に 得られ，当科でも $84.6 \%$ とほぼ満足出来る成績となっ ている（表 3 ). 中心性脱臼に対しては, 大転子から の側方牽引を追加した保存的治療が行われてきたが, 整復されない場合が多く，また長期間の臥床を要する. 臼蓋底, quadrilateralsurface の整復固定に Cole ら は は plateを用いたが，小骨盤腔の深い部位で非常 に難しいため，我々はケーブルと骨移植を併用した方 法を用いた。 plateに比べると固定が容易で，屯し将 来変形性関節症を来したときの目蓋底の bone stock にもなる利点がある(図 5 ).

\section{ま と め}

1) 寛骨臼両柱骨折に対し観血的治療した 13 例につ いて検討した。

2 ) 侵襲は大きいが, 関節面の解剖学的整復と早期離 床が可能であった。
3 ）ケーブルと骨移植を併用することで，臼蓋底骨片 の整復固定が可能であった。

\section{参 考 文 献}

1) Alonso J. E. et al. : Extended iliofemoral versus triradiate approaches in management of associated acetabular fractures. Clin Orthop., 305 : 81-87, 1994.

2) Bray T. J. et al. : Osteotomy of the trochanter in open reduction and internal fixation of acetabular fractures. J. Bone Joint Surg., 69-A : 711-717, 1987.

3) Cole J. D. and Bothofner B. R. : Acetabular fracture fixation via a modified Stoppa limited intrapelvic approach. Clin Orthop., 305:112-123, 1994.

4) Goulet J. A. and Bray T. J. : Complex acetabular fractures. Clin Orthop., 240:9-19, 1989.

5) Moroni A. et al. : Surgical treatment of both column fractures by staged combined ilioinguuinal and Kocher-Langenbeck approach. Injury, $26: 219-224,1995$.

6) Reinert C. M. et al. : A modified extensile exposure for the treatment of complex or malunited acetabular fractures. J. Bone Joint Surg., 70-A : 711-717, 1988.

7) Ruott M. L. C. et al. : Operative treatment of complex acetabular fractures. J. Bone Joint Surg., 72-A : 897-904, 1990. 